\title{
Environmental management for Agriculture: An Expert System Approach
}

\author{
P. Tucker, K.A. Lewis \& J.A. Skinner \\ Division of Environmental Sciences, University of Hertfordshire
}

\begin{abstract}
The development of quantitative measures for self-assessment of the environmental performance of farming enterprises is described. A rule-based expert system approach is adopted based on well established sources of guidance. Value judgements are introduced as configurable coefficients. The system derives a compound performance indicator which can provide the basis for inter- or intra-farm comparisons and also provides an objective criterion on which the concept of continuing environmental performance can be judged. This method can also be used to provide an empirical check on environmental sustainability. The evaluations within the system are based on whether actions have, on balance, the potential to result in net environmental harm or benefit. The role of such evaluations within an integrated decision support framework is discussed.
\end{abstract}

\section{Introduction}

Farming as an activity operates through modifying the natural environment. Although in the past the consequences of this were often accepted without question, there is now a mounting concern over both the short- and long-term environmental impacts that might occur as the result of farming activities. Increasingly stringent regulation is forcing the farming community to substitute many traditional practices with more environmentally acceptable alternatives, e.g. for stubble- disposal, and is prompting a reconsideration of the potential impacts from many routine practices such as agrochemical application. Public and supply chain pressures are also beginning to become significant driving forces towards more sustainable practices.

To move towards a more environmentally conscious farming system can present the farmer with many options to consider and often with difficult decisions to make. The solutions are not straightforward. Many diverse factors need to be interrelated, often depending on value judgements rather than hard facts. Options can conflict. For example, some mitigating measures to control nitrate leaching could result in increased emissions of greenhouse gases. How does a farmer rank one against the other? How can the totality of the impact be rationalized? Past activities should not be neglected as poor historical practices might have already degraded environmental quality - for example, through erosion, mineral excesses or toxic residues in soils. Natural attenuation of excesses and residues can take considerable time. Inappropriate action now can similarly leave its own legacy for future generations.

The problem of how to sustain environmental improvement while maintaining economic growth presents challenges to the farmer and requires careful appreciation of all the risks and benefits that can ensue. These are all complex problems and, as yet, no universal solution can be offered, although much guidance is available. The Codes of Good Agricultural Practice (Anon., 1991; 1992; 1993) published by the UK Ministry of Agriculture, 
Fisheries and Food (MAFF)provide sound environmental advice for the management of soil, water and air and are complemented by other good reference sources (e.g. Canter, 1986; Park, 1988; Powlson, 1993; Association of Applied Biologists, 1992; Davis et al., 1993). There is not a paucity of information. The problem facing the farmer is how to distil this information into a coherent action plan.

The commitment to good environmental management still relies heavily on voluntary action. Formal environmental management schemes such as BS7750 (British Standards Institution, 1994) can be applied to agricultural enterprises and again professional and general guidance is becoming available for the implementation of such schemes (Anon., 1995a; 1995b). If, however, a less formal approach is preferred, then it should be pursued. One underlying concept which needs to be considered in any approach is a commitment to continuing environmental improvement. This implies periodic evaluation against a baseline, the establishment of such a baseline being an early priority. One approach for this is through a self assessment questionnaire or checklist. The LEAF (Linking Environment and Farming) organization adopted this type of approach using a broadly based, though largely qualitative' audit' questionnaire (Blake, 1994). Although providing a useful catalyst for selfanalysis, the scope of the LEAF audit does not, however, readily lend itself to the establishment of qualitative performance indicators nor to any holistic appraisal of the overall farm performance.

This paper presents the next step in farm appraisal methodologies. It describes how the environmental performance baseline might be established on a more quantitative basis and how continuing environmental improvement could be evaluated. This evaluation, however, must be viewed as just one facet of the decision support that should be available to the farming industry. Access to sources of guidance and awareness of legislation, for example, are equally important to the farmer in formulating any sustainable development plan. The paper concludes by summarizing our initial decision support system, based on these concepts, for sustainable development in the agricultural industry.

\section{A Farm Performance Evaluation}

Environmental performance evaluation needs to set objective criteria against which actual performance can be judged. Such criteria can be set empirically as specific targets of a farm environmental policy or can be expressed more generically in terms of comparable or absolute measures. Comparative measures can include both time-based assessments (continuing improvement) or assessments against the performance of a 'model' farm where good practice is observed. Absolute measures could include a check for sustainability. The work presented here concentrates on the development of some possible generic measures.

Clearly many individual and diverse factors will contribute in combination to the overall performance. An important requirement of any evaluation system is a mechanism to enable these factors to be combined in a rational, reproducible and acceptable way. The problems in establishing such a mechanism are well known. One commonly used approach is a simple scoring system, each impact or indicator being given a numerical score based on its magnitude and/or significance, with the total score representing the total impact. Examples can be cited for environmental impact assessment (e.g. Leopold et al., 1971;Solomon et al., 
1977; Lee, 1987), life cycle analysis and site assessment studies (Tucker and Perguson, in press). Although often criticized for over-simplicity (e.g. Thompson, 1988), this method can provide an essential starting point, and perhaps the only practical means, for systems whose underlying complexities are not fully understood or agreed. The scoring approach was adopted here. The mapping of individual practices or actions into a numerical score was accomplished through a set of 'expert system' rules. The score range was set at +10 (maximum positive impact) to -10 (maximum negative impact) for individual impacts. The value 0 represents an environmentally neutral practice.

The kernel of the rule base was established from UK Government publications, including MAFF Codes of Good Agricultural Practice, Codes of Recommendations for the Welfare of Domestic Fowls (Anon., 1990a), Codes of Recommendations for the Welfare of Pigs (Anon., 1990b), Codes of Practice for the Safe Use of Pesticides on Farms and Holdings (Anon., 1990)and Fertiliser Recommendations for Agriculture and Horticultural Crops, RB 209 (Anon., 1994). Additional heuristics were elicited from leading practitioners in the industry. Examples of the derived rules are given in the following. These examples make specific reference to fertilizer application.

\section{Rule 1: nitrogen application rates (nitrate leaching)}

This rule compares actual amounts of soil mineral N with that recommended by RB 209 (Anon., 1994). Recommendations are crop-specific and consider soil type, the amount of mineral already in the soil, either by analysis or based on the previous crop and any organic manure, sewage sludge or other soil conditioner applications. The scoring system is based on the relative error on the recommended application.

Score $\left(S_{1}\right)=$ integer $[10 \times($ recommended - actual/recommended $)]$

where if $\left[S_{1}\right]>10$ the $\left[S_{1}\right]=10$.

Clearly, if less fertilizer than recommended is applied, the potential for leaching is low and the possibility of consequential environmental impact is small. Although -this- results in a positive environmental impact from this rule, this does not imply that it is in fact good practice. Crop yields may suffer and soil degradation may occur. Resultant soil degradation is accounted for in a separate rule.

\section{Rule 2: N, P, K levels (soil degradation)}

If phosphate $(P)$ and potash $(K)$ fall below maintenance levels, then soil degradation may occur (Davis et al., 1993). Equivalent rules can be assigned (heuristically) for N. If soil is not being sustained, $S_{2}=-10$, else $S_{2}=0$.

\section{Rule 3: rainfall (nitrate leaching)}

If rainfall is above average (a default value of $900 \mathrm{~mm}$ per year is taken as the average), then if the actual $\mathrm{N}$ applications exceed the recommended levels, the risk of leaching is increased. The scale of this risk depends on the soil type, the depth of soil and the underlying rock. These are considered as far as possible in the soil type classification.

Score $\left(S_{3}\right)=$ integer $[10 \times T \times$ (average - actual rainfall/average) $]$ 
If the actual rainfall is greater than average, else $S_{3}=0$. T is a scaling parameter for soil type; $T=1.0$ (sandy or shallow soils), 0.8 (organic or peat), 0.6 (silt) or 0.4 (clay).

\section{Rule 4: fertilizer application timing (nitrate leaching)}

Correct timing is important to ensure that crops make the maximum use of the $\mathrm{N}$ available. Too early an application increases potential leaching. Too late an application may result in impaired crop growth. Recommendations are given in RB 209, with additional advice provided by the Code of Good Agricultural Practice for the protection of Water. The guidance on timing in RB 209 is often specific (e.g. early May, six weeks after planting, etc.), which in practice may not always be acceptable. For example, if it rains when the application should have been made, then the farmer cannot be penalized. More environmental damage may be done by rigidly meeting the deadline. The application rules have therefore been designed to provide a wider tolerance on timing (e.g. spring, seedbed, split seedbed/spring, etc.). These rules, by necessity, are crop-specific and consider existing soil $\mathrm{N}$, recommended additions of $\mathrm{N}$, soil type and in some instances individual crop variety.

For example, consider main-crop potatoes on a sandy soil with average $\mathrm{N}$ levels. If the crop is irrigated, then fertilizer addition should be split, half in the seedbed and half at tuber initiation: $S_{4}=+10$ if the application timing is correct; $S_{4}=+5$ if the application is all in the seedbed or all in spring; $S_{4}=-10$ if the application is late autumn or winter and the crop does not require it; and $\mathrm{S}_{4}=0$ otherwise.

\section{Summary}

In all, well over 70 rules have been identified for fertilizer application alone, with special rules considering fertilizer application in environmentally sensitive areas. Similar rule bases are under development for pesticides, farm waste management, soil erosion and general performance assessment. These general performance assessment rules cover diverse concerns, not considered elsewhere, such as hedgerow management, woodland management and animal welfare. Approximately 300 rules have so far been identified for these concerns.

An overall performance assessment is achieved by aggregating the individual scores into a single performance parameter $\mathrm{S}$.

$\mathrm{S}=\left[\left(S_{\mathrm{i}} \bullet W_{\mathrm{i}}\right) \mathrm{i}\right]$

Where $w_{i}$ is a weighting factor describing the relative importance of each rule against all the others. Currently values of $w_{i}$ have been set according to the authors' best opinion. These default values are not considered to be prescriptive and will inevitably evolve as wider expert consensus is reached and more practical understanding is gained. If a system user has good reasons to override the default value, then they should do so.

The overall performance indicator, $S$, provides the comparative measure of environmental performance. The methodology will generate $S$ indices most precisely when the evaluation is performed on a field by field basis, although aggregated whole farm values can equally be estimated. The scale of S values given by Equation (3) is fairly arbitrary, though consistent 
for both inter-farm and intra-farm comparisons. A positive $S$ value indicates a probable overall beneficial affect on the environment, whereas a negative $S$ value implies a probable detrimental effect. The value $S=a$ (environmentally neutral) might be taken as the threshold of sustainability. It is often more helpful to the practitioner if the evaluation scale is normalized and bounded, say +100 to -100 , so that it can then be related in absolute terms to performance against the best and worst case scenarios. This normalization, however, limits the scope for inter-farm comparisons unless local factors happen to be similar between the two units.

\section{User Input Requirements}

The demands of the 'expert system' rule base establish precise input requirements for the system. No redundant information needs to be requested. The first stage of the assessment involves the specification of local farm data. This includes, for example, the farm's geographical location, size, local climate, soil types, soil nutrient analyses, soil $\mathrm{pH}$ and outline details of farming operations. Other relevant information may also be required, such as the presence of nearby surface waters, archaeological features and whether or not the land is classified under any special environmental status. These data should be readily available to the farmer.

Once the local information has been established, the user must then respond to an 'audit' questionnaire. The audit is divided into sub-audits relating to soil fertilizer application, pesticides, energy management, waste management, habitat conservation and animal welfare. The audit and its evaluation, if preferred, can be restricted to individual issues, such as energy management. The requested response can range from a simple categorical reply (yes/no or true/false), through multiple choice answers to the input of specific quantitative information, e.g. 'how much fertilizer $\mathrm{N}$ is applied ( $\mathrm{kg} / \mathrm{ha})$ ?' The multiple choice approach helps to avoid leading questions, which can prove particularly important when elements of good and bad practice are found together with a single activity.

\section{Discussion}

The performance measure, $S$, can provide a farm with a local baseline on which an assessment of environmental improvement can be based. However, although these methods will perform 'better' or 'worse' comparisons adequately, they cannot give absolute measures other than on an empirical local scale. This scale depends on value judgements made on the relative importance of diverse effects and practices. These value judgements are not prescriptive and can be configured to meet local objectives and criteria or made to reflect specific expert opinion. There is no right answer. This lack of absoluteness should, however, not be seen as a cause for concern. The system is, after all, only a support tool to help farmers make more informed decisions and to help reduce the risk involved in those decisions. It is not intended to exercise judgement on the farmer.

The index $S$ is based primarily on the evaluation of activities and, as such, provides a measure of whether individual activities have the potential to cause effects that are not either beneficial or detrimental to the environment. The value of $S$ does not establish 
whether or not the activities will cause such impacts. For example, although a potential for leaching might be identified (say, for pesticides), it does not follow that the pesticides will be leached into a water course - they may be sorbed onto soil particles or degraded in the soil- nor does it follow that, if on reaching a water course, concentration levels will be sufficient to give concern (the EU legal limit of $0.1 \mathrm{ug} / \mathrm{l}$ might be taken as the threshold for concern). To evaluate whether an activity will actually result in an impact would require a second stage of analysis. This stage will be subject to additional uncertainties and require new assumptions based largely on an understanding of the externalities involved. In some instances it might be possible to use quantitative models for this analysis and to estimate the resulting environmental burdens, although value judgements would be necessary to interpret these burdens as environmental impacts.

\section{An Integrated Decision Support System}

A means for a structured farm evaluation provides one tool for realizing the commitment to good environmental management. Any recommendations arising from the evaluation need to be supported by sound evidence. This is provided through cross-referencing the evaluation system with the source publications that provide the basis for the rules. In the software implementation of the system, context-sensitive mapping provides hypertext jumps from the evaluation system directly to the relevant source-material. These sources of guidance can also be accessed independently of the evaluation system, with crossreferencing within and between individual texts being provided by further context-sensitive jumps. A third component of the system provides the technical support, including models and databases (for example, a database on average rainfall for England and Wales). The technical support module is also free-standing and is automatically consulted by the evaluation system when required. The system is shown structurally in Figure 1 . The integrated system is written primarily in Visual Basic and is PC-based running under the Windows operating system.

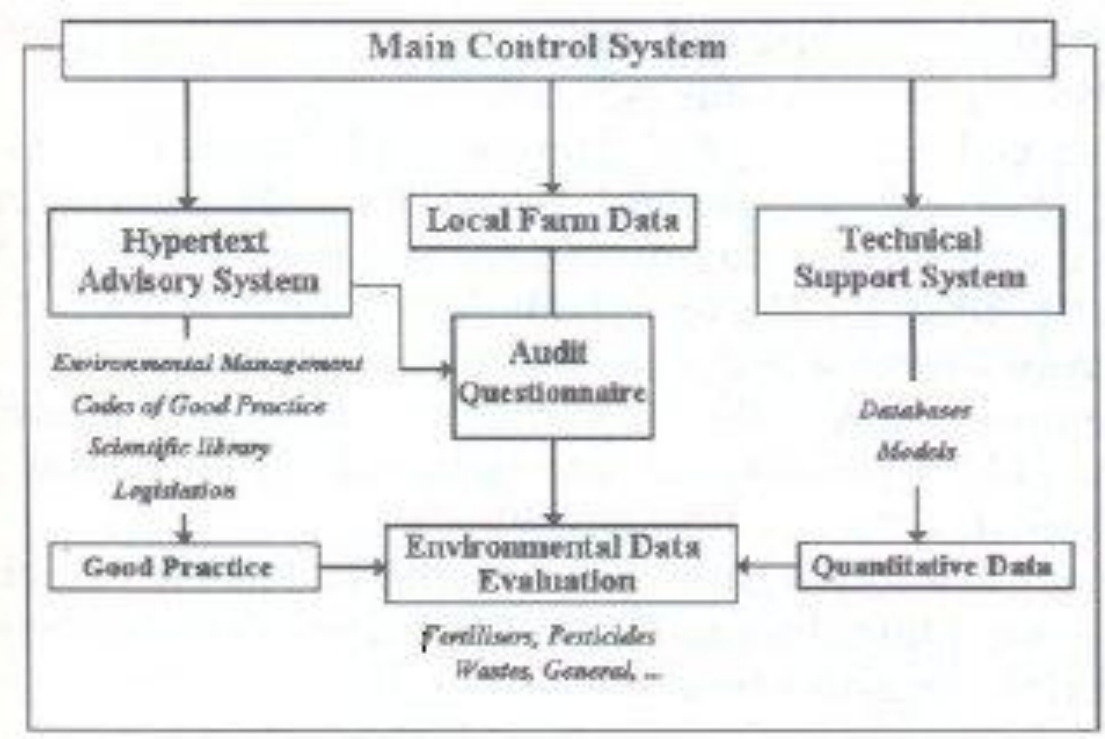

\section{Figure 1. System structure.}




\section{Conclusions}

The drive towards increasing environmental accountability is progressively affecting the agricultural industry. Farmers are faced with complex decisions on how best to improve environmental performance without jeopardizing profitability. Decision support to farmers is already provided in much reference material, although some of this advice may appear to conflict according to the environmental emphasis that has been adopted.

Farmers also need to develop a means of evaluating environmental performance against a defined benchmark. A mechanism for this evaluation has been developed based on an audit' questionnaire and 'expert system' analysis using established rules of guidance extracted from quality reference sources. It is recognized that such a system can never produce an absolute measure of environmental performance, nor can it ever be free of value judgement. To be flexible and acceptable to all, these value judgements must be both transparent and configurable. In the system developed here the judgements are represented as a series of adjustable numerical coefficients. Their values are not prescriptive and will evolve with time as understanding develops.

The evaluation must be constrained (for the time being) to estimates of whether actions, policy or procedures, singly or in combination, produce the potential to cause environmental harm or benefit. The performance criteria derived can form the basis for an environmental performance evaluation: (i) against expectations for a 'model' farm; (ii) as a test of continuing environmental improvement within the context of a farm environmental management system; and (iii) as an indicative check for sustainable development. These evaluations are not absolute measures; they simply provide reasoned support to help the farmer make some of the complex decisions involved in running a business. The system prototype is currently under evaluation by leading practitioners from the farming industry. The information and rule bases within the prototype have been focused on England and Wales; however, it is believed that the concepts should be generally applicable.

\section{Acknowledgement}

The work was funded by the UK Ministry of Agriculture, Fisheries and Food and was carried out in collaboration with IACR Rothamsted and ADAS. The advice of John Catt (IACRRothamsted) and Nick Nicholson and Brian Chambers (ADAS) is gratefully acknowledged. The views expressed in this paper are those of the authors and are not necessarily those held by the Ministry.

\section{References}

Anon. (1990) Code of Practice for the Safe Use of Pesticides on Farms and Holdings, HMSO, London.

Anon. (1990a) Codes of Recommendations for the Welfare of Domestic Fowls, MAFF Publications, London.

Anon. (1990b) Codes of Recommendations for the Welfare of Pigs, MAFF Publications, London. 
Anon. (1991) Code of Good Agricultural Practice for the Protection of Water, MAFF Publications, London.

Anon. (1992) Code of Good Agricultural Practice for the Protection of Air, MAFF Publications, London.

Anon. (1993) Code of Good Agricultural Practice for the Protection of Soil, MAFF Publications, London.

Anon. (1994) Fertiliser Recommendations for Agriculture and Horticultural Crops (RB 209), HMSO, London.

Anon. (1995a) An Introductory Guide to BS 7750 for Agriculture and Commercial Horticulture, ATB Landbase, Stoneleigh Warwickshire.

Anon. (1995b) BS 7750: Sector Application Guidelines for Agriculture and Commercial Horticulture, ATB Landbase, Stoneleigh Warwickshire.

Association of Applied Biologists (1992) Aspects of Applied Biology 30, Nitrate and Farming Systems, Horticulture Research International, Wellesbourne.

Canter, L.W. (1986) Environmental Impacts of Agricultural Production Activities, Lewis, Chelsea.

Blake, A. (1994) Leaf audit: step in right direction. Farmers Weekly, 2 Sep.

British Standards Institution (BSI) (1994) British Standard BS 7750, BSI, London.

Davies B., Eagle D. and Finney B. (1993) Soil Management, Farming Press, Ipswich.

Lee, N. (1987) Environmental Impact Assessment: a Training Guide, Occasional Paper 18, Department of Town and Country Planning, University of Manchester.

Leopold, L.B., Clarke, F.E., Hanshaw, B.B. and Basley J.R. (1971) A procedure for evaluating environmental impact, Circular 645, US Geological Survey, Washington.

Park, J.R. (Ed.) (1988) Environmental Management in Agriculture: European Perspectives, Belhaven Press, London.

Powlson, D.S. (1993)Agriculture, Scientific Basis for Codes of Good Agricultural Practice. Farming, Fertilisers and the Nitrate and Phosphate Problems, Commission of the European Communities, Luxembourg.

Solomon, R., Colbert, B.K, Hansen, W.J., Richardson, S.E., Canter, L. and Vlachos, E.C. (1977) Water Resources Assessment Methodology (WRAM) Impact Assessment and Alternative Evaluation, Technical Report Y-77-I, US Army Corps of Engineers, Vicksburg.

Thompson, M.A. (1990) Determining impact significance in EIA: a review of 24 methodologies, Journal of Environmental Management, 30.

Tucker, P. and Ferguson C. A methodology for optimising sampling designs for contaminated sites, Mathematical Geology, in press.

\section{Biography}

The authors may be contacted at:

Division of Environmental Science,

University of Hertfordshire,

Hatfield Campus,

College Lane, Hatfield,

Hertfordshire ALIO 9AB, UK.

Tel.: 01707284528.

Fax.: 01707284514.

E-mail: KA.Lewis@herts.ac.uk 